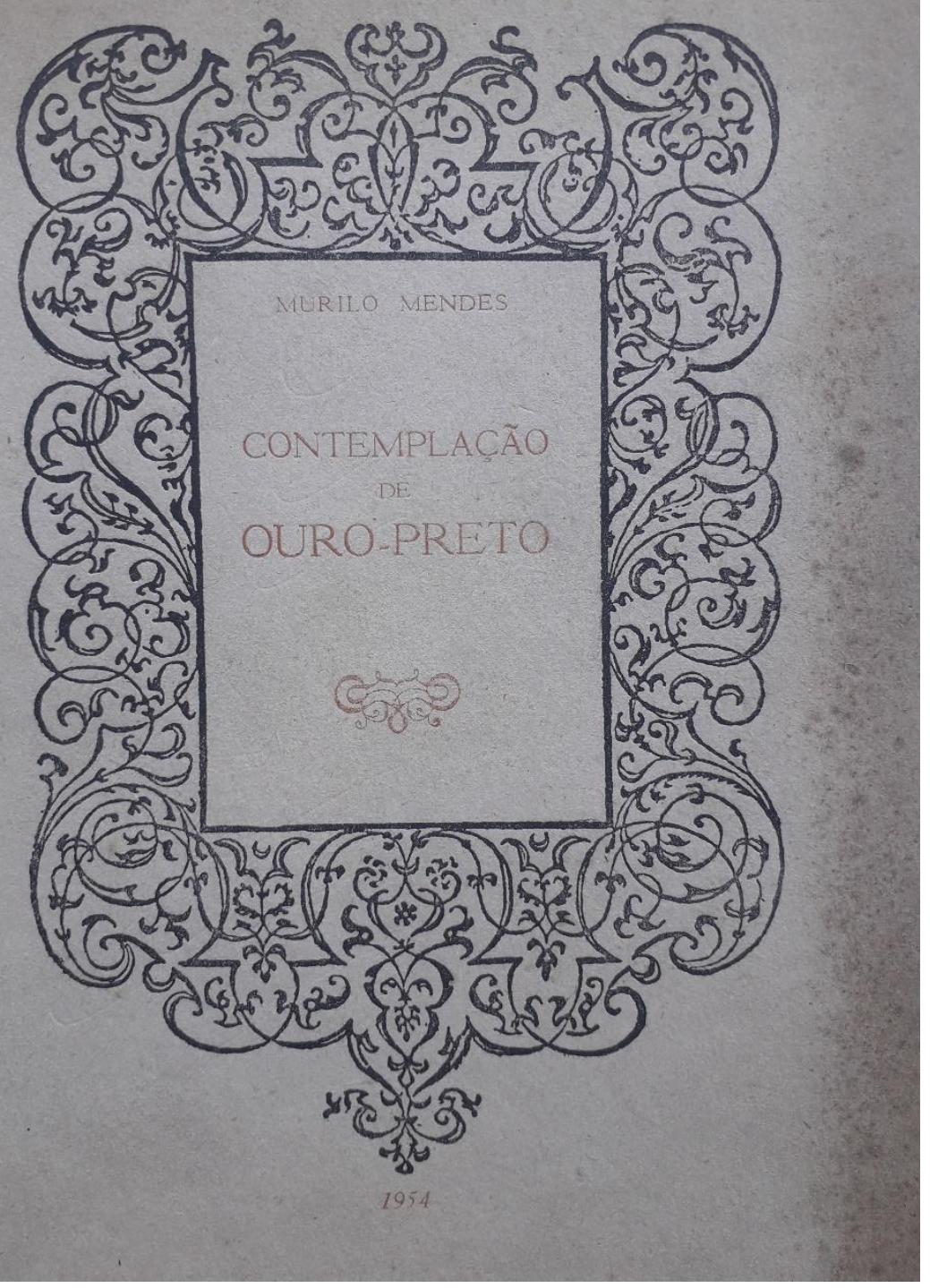

\title{
Aleijadinho por Murilo Mendes
}

Aleijadinho by Murilo Mendes

Dra. Raquel Quinet Pifano

Como citar:

PIFANO, R.Q. Aleijadinho por Murilo Mendes. MODOS. Revista de História da Arte. Campinas, v. 4, n.2, p.163-179, mai. 2020. Disponível em: <https://www.publionline.iar.unicamp.br/index.php/mod/article/ view/4570 > . DOI: https://doi.org/10.24978/mod.v4i2.4570.

Imagem: Folha de rosto do livro "Contemplação de Ouro Preto" de Murilo Mendes, Ministério da Educação e Cultura - Serviço de Documentação edição de 1954. Foto da autora. 


\section{Aleijadinho por Murilo Mendes}

\section{Aleijadinho by Murilo Mendes}

\section{Dra. Raquel Quinet Pifano*}

\section{Resumo}

Este artigo visa examinar a imagem de Aleijadinho apresentada no livro Contemplação de Ouro Preto de Murilo Mendes. Visa comparar a descrição de Aleijadinho de Murilo com as dos intelectuais modernistas, incluindo a de Manuel Bandeira em Guia de Ouro Preto. Busca apurar seu conceito de artista e as relações entre nacional e universal na arte.

\section{Palavras-chave}

Aleijadinho. Murilo Mendes. Artista moderno.

\section{Abstract}

This paper is an attempt to examine the image of Aleijadinho presented by Murilo Mendes in Contemplação de Ouro Preto. It aims to compare Murilo's description of Aleijadinho with those of modernist intellectuals, including that of Manuel Bandeira in Guia de Ouro Preto. Furthermore, it seeks to investigate Murilo's concept of artist and the relations between national and universal in art.

\section{Keywords}

Aleijadinho. Murilo Mendes. Modern Artist. 
Entre 1949 e 1950 Murilo Mendes escreveu Contemplação de Ouro Preto, que foi publicado em 1954 pelo Serviço de Documentação do Ministério da Educação e Cultura, Departamento da Imprensa Nacional, com bela edição acompanhada de fotografias de Humberto Moraes Franceschi e Enrique Hess. Esta obra inaugura, pode-se dizer, uma nova fase na poesia de Murilo, marcada por uma maior atenção às coisas e à paisagem, assim como à história e à tradição do Brasil. 0 tema da história do Brasil já havia sido alvo de atenção do poeta em 1932 quando publicou História do Brasil pela Ariel Editora - esta edição trazia capa de Di Cavalcanti. Embora ambas as obras se dediquem à história do Brasil, o fazem de maneiras bem diferentes. Em História do Brasil prevalece a crítica histórica em tom satírico, sendo considerado um livro de poemas-piada (Aragão: 1983). Já em Contemplação de Ouro Preto o tom de sátira desaparece, apresentando-se como expressão de uma memória histórica e literária. Através da abordagem do espaço da cidade de Ouro Preto e da presença de personagens históricas da cultura brasileira, como Tiradentes e Aleijadinho, o tempo passado é aludido. Quanto à mudança no tratamento da história entre as duas obras, Valmir de Souza pondera: "A escrita do livro sofre o influxo de intensas conversas com o historiador português, conhecedor da cultura ibérica, o que teria levado o poeta a repensar sua visão sobre a colonização, antes vista de forma ridícula" (Souza, 2006: 133).

O historiador português a que Souza se refere é Jaime Cortesão. Murilo, segundo o seu próprio testemunho, conheceu-o em 1940, logo depois de sua chegada ao Brasil para cumprir seu exílio:

Confesso que no limiar de nossas relações ele me intimidava um pouco. De fato, eu vivia - e ainda vivo - no meio de poetas, escritores, artistas plásticos, músicos, mas não praticara até então nenhum historiador. (...) Neste campo, só me distinguia o fato de haver publicado uma História do Brasil onde eu troçava não só dos portugueses, mas também dos brasileiros; (...) achei preferível entrincheirar-me na humildade: quando Cortesão falava de história eu ouvia, aprendia. Assim foi pela vida afora (...) (Retratos-Relâmpago, Mendes: 1994: 1287).

De fato, como afirmou Marcondes de Moura (1995), o encontro e a estreita convivência com dois portugueses exilados no Brasil, Maria Helena Vieira da Silva e Jaime Cortesão, durante os anos 1940 irão marcar dois elementos fundamentais na poesia futura de Murilo. Do encontro com Maria Helena Vieira da Silva resultaria uma maior preocupação com as questões formais da sua escrita poética; já com Jaime Cortesão, uma nova atenção para o sentido da história e da tradição.

Em Retratos-Relâmpago (1973-74), ao retratar Jaime Cortesão, Murilo ressalta que teve "o privilégio de realizar em sua companhia algumas excursões no interior do Brasil, e muitas outras em Portugal" (Mendes, 1994: 1289). Murilo lembra que o sogro (Murilo casou-se com Maria da Saudade, filha do historiador, em 1947) definia Ouro Preto como "a mais portuguesa das cidades" e reconhece Cortesão como um guia:

Pilotado por um tal guia é óbvio que minha visão da terra e do povo português ampliou-se consideravelmente, mesmo no plano literário, quando ele me ilustrava trechos de Camões, de Gil Vicente, João de Barros, Fernão Mendes Pinto, Frei Luis de Sousa e outros, ligandoos à respectiva história e situação político-social. Direi ainda que era entendido em artesplásticas, o que aumentava o prazer de sua convivência (1994: 1289/90). 
Infelizmente Murilo não registrou a data de tal "excursão", mas o mais provável é que tenha ocorrido antes ou durante a escrita de Contemplação. Considerando que em 1952, o poeta embarca para a Europa a serviço do Ministério das Relações Exteriores do Brasil para cumprir missão de divulgação da cultura brasileira, retornando em 1956, para transferir-se definitivamente para Roma no ano seguinte com a incumbência de assumir a cadeira de Estudos Brasileiros na Universidade de Roma, haveria pouco tempo disponível para a viagem com sogro. Ademais, em 1957 Jaime Cortesão retorna a Portugal. A convivência, o debate ou aprendizagem da visão da história de Cortesão certamente influíram na mudança de concepção da história e memória do Brasil operada por Murilo. Cortesão, como afirmou Murilo, certamente foi um guia.

Contudo, ao que tudo indica, o historiador Jaime Cortesão não fora seu único guia. Durante o Carnaval de 1951, Murilo e Maria da Saudade voltariam a Ouro Preto em companhia de sua irmã Virginia e seu marido Paulo Torres. Conforme relato de Torres, durante a estadia eles conviveram "em certo grau de intimidade" com alguns amigos de Murilo: o casal Graciema e Rodrigo de Mello e Franco de Andrade, diretor do IPHAN, o casal Lucia Machado de Almeida e Antônio Joaquim de Almeida, então diretor do Museu do Ouro de Sabará, e o arquiteto Sylvio de Vasconcellos, diretor regional do IPHAN. Hospedaram-se, como seria de se esperar, no Grande Hotel, prédio projetado por Oscar Niemayer. Segundo seu cunhado, "o poeta passava horas na varanda do hotel, como num êxtase, contemplando do alto os lindos telhados e a cidade como um todo" (Torres, 2005: 299).

Como referido, Contemplação foi escrito entre 1949 e 1950, mas publicado em 1954; a viagem com o grupo do SPHAN foi em 1951'. Sabemos que Murilo sempre revisava seus textos antes das publicações, chegando mesmo a fazer algumas alterações (Picchio in Mendes, 1994). Logo, não é despropositado supor que algumas dedicatórias dos poemas que compõem Contemplação tenham sido atribuídas depois desta viagem. É o caso dos poemas Romance das Igrejas de Minas dedicado a Rodrigo Mello Franco de Andrade, Adão e Eva dedicado a Antônio Joaquim de Almeida e Lúcia Machado de Almeida, A Igreja de Ouro Branco dedicado a Sylvio de Vasconcellos, Crucifixo de Ouro Preto dedicado a sua irmã Virginía e Sacristia do Carmo de Ouro Preto dedicado a Graciema M. F. de Andrade. Murilo também dedicou seus poemas ao crítico Ruben Navarra e ao pintor Alberto da Veiga Guignard. Significativas também são as dedicatórias de Flores de Ouro Preto a Cecilia Meirelles, Romance de Ouro Preto a Manuel Bandeira, Montanhas de Ouro Preto a Lourival Gomes Machado, São Francisco de Assis de Ouro Preto a Lucio Costa e Luminárias de Ouro Preto a Gustavo Capanema. Ao se considerar as dedicatórias vai se delineando os demais "guias" de Murilo na sua recriação de Ouro Preto.

Alguns títulos encontrados na biblioteca de Murilo também nos orientam sobre os seus interlocutores no processo de criação de Contemplação. Chama a atenção a presença do Guia de Ouro Preto de Manuel Bandeira (edição de 1947), e os títulos Retrato da arte moderna no Brasil (1947) e Teorias do Barroco (1953) ambos de Lourival Gomes Machado ${ }^{2}$ - frise-se que são livros marcados e anotados por Murilo. Sendo a primeira edição do Guia de Ouro Preto de 1938, é sugestivo o fato de a edição de Murilo ser de 1947, período em que coincide com um momento em que o poeta se interessa mais pela história e tradição cultural do Brasil. O Guia de Bandeira é atravessado pelos anseios modernistas de 
preservação do patrimônio histórico e artístico nacional, em que Ouro Preto é elevada à condição de símbolo deste patrimônio, vinculando assim a tradição artística brasileira ao passado colonial. Tudo isso embalado por um fundo nacionalista, onde Tiradentes e Aleijadinho são alçados à condição de heróis nacionais.

Contemplação de Ouro Preto, de certa forma, atualiza as imagens de passado e tradição artística brasileira forjadas pelos intelectuais modernistas e institucionalizadas pelo SPHAN. Marca o texto de Murilo o tom de urgência de preservação do Patrimônio Histórico - Ouro Preto. Para Valmir de Souza, "Contemplação poderia ser considerada, no campo literário, um objeto-síntese do ideário da geração de intelectuais voltados para a preservação do patrimônio histórico-cultural do Brasil" (2006: 148). Vejamos como a imagem de Aleijadinho foi construída e difundida pelos intelectuais ligados ao SPHAN.

\section{Aleijadinho sob a ótica do SPHAN}

Antônio Francisco Lisboa, o Aleijadinho, é o artista brasileiro talvez mais conhecido entre os brasileiros e certamente o mais debatido entre os seus estudiosos. Inegável a contribuição dos modernistas na identificação e consolidação de sua condição de herói nacional, entretanto não Ihes pode ser atribuída a invenção da imagem de artista genial desfigurado por uma enfermidade desconhecida, imagem fundadora. Esta história tem origem em meados do século XIX, com Rodrigo José Ferreira Bretas.

Bretas foi homem ilustre da província de Minas: professor de filosofia e retórica em Barbacena e Ouro Preto, Promotor Público Interino na Comarca de Ouro Preto, Deputado provincial por quatro vezes, Inspetor da Instrução Pública, diretor de colégios em Ouro Preto e Cachoeira do Campo entre outros. Além disso, foi agraciado pelo Imperador com a Ordem da Rosa. Em 1858, publicou no Correio Oficial de Minas "Traços biográficos relativos ao finado Antônio Francisco Lisboa, distinto escultor mineiro, mais conhecido pelo apelido de Aleijadinho". Com esta monografia, Bretas foi aprovado como sócio correspondente do Instituto Histórico e Geográfico Brasileiro. Suspeita-se que nosso autor tenha escrito a referida monografia visando justamente concorrer ao posto de sócio correspondente do prestigiado Instituto. Ora, para tal o texto deveria atender às expectativas românticas e nacionalistas do Instituto.

Criado em 1838, o Instituto Histórico e Geográfico Brasileiro (IHGB) reuniu em torno de si a intelectualidade brasileira da época. Herdeiro da tradição iluminista, surgiu com o intuito de "produzir uma reflexão sistemática sobre os problemas da nação e do Estado emergentes" (Gomes Jr, 1998: 35). Desde suas primeiras pesquisas, buscou integrar grupos indígenas, negros e mulatos, assim como as histórias regionais, num amplo projeto de construção nacional destinado a transformar geopoliticamente o território em Nação. Como estratégia para chegar à desejada unidade nacional, o Instituto incentivou os estudos de história regional, através dos quais seria possível unir as várias regiões ao centro do Império. Daí, a criação de muitos Institutos Históricos regionais que realizavam pesquisas e as enviavam à sede principal no Rio de Janeiro. Material com o qual os membros efetivos, residentes na capital, construíam a história nacional. Tal programa foi implantado desde a criação do Instituto, que solicitava aos sócios correspondentes notícias minuciosas sobre suas respectivas províncias, fossem de caráter histórico, geográfico ou etnográfico. Calcados num modelo de História oriundo da velha noção de história magistra vitae, os pesquisadores do Instituto buscavam no resgate de episódios emblemáticos do passado fornecer às novas gerações modelos de força e virtude, "contribuindo desta forma para a 
construção da galeria dos heróis nacionais" (Revista do IHGB-RJ, 1847 apud. Grammont, 2002:88). Foi neste espírito que a Revista Trimestral do Instituto dedicou às biografias de personalidades históricas a seção "Biografia dos Brasileiros Distintos por Letras, Armas, Virtudes etc". E foi neste espírito que Rodrigo Jose Ferreira Bretas escreveu a monografia sobre o "distinto escultor mineiro". Assim Bretas descreve Aleijadinho:

Antônio Francisco era pardo escuro, tinha voz forte, a fala arrebatada, e o gênio agastado: a estatura era baixa, o corpo cheio e mal configurado, o rosto e a cabeça redondos, e esta volumosa, o cabelo preto e anelado, o da barba cerrado e basto, a testa larga, o nariz regular e algum tanto pontiagudo, os beiços grossos, as orelhas grandes, e o pescoço curto. (...)

De 1777 em diante, as moléstias, provindas talvez em grande parte de excessos venéreos, começaram a ataca-lo fortemente. (...) 0 certo é que, ou por ter negligenciado a cura do mal no seu começo, ou pela força invencível do mesmo, Antônio Francisco perdeu todos os dedos dos pés, do que resultou não poder andar senão de joelhos; os das mãos atrofiaram-se e curvaram, e mesmo chegaram a cair, restando-hhe somente, e ainda assim quase sem movimento, os polegares e os índices. As fortíssimas dores de que contínuo sofria nos dedos, e a acrimônia de seu humor colérico o levaram por vezes ao excesso de cortá-los ele próprio, servindo-se do formão, com que trabalhava! As pálpebras inflamaram-se, e permanecendo neste estado, ofereciam à vista sua parte interior; perdeu quase todos os dentes, e a boca entortou-se, como sucede frequentemente ao estuporado; o queixo e o lábio inferior abateram-se um pouco; assim, o olhar do infeliz adquiriu certa expressão sinistra e de ferocidade, que chegava mesmo a assustar a quem quer que 0 encarasse inopinadamente. Esta circunstância, e a tortura da boca, o tornavam de um aspecto asqueroso e medonho. (...)

A consciência que tinha Antônio Francisco da desagradável impressão que causava sua fisionomia o tronava intolerante, e mesmo iroso para com os que lhe parecia observaremno de propósito; entretanto, ele era alegre e jovial entre as pessoas de sua intimidade.

(...) Depois da fatal enfermidade que o acometeu, trajava uma sobrecasaca de pano grosso azul que the descia até abaixo do joelhos, calça e colete de qualquer fazenda, calçava sapatos pretos de fôrma análoga aos pés, e trazia, quando a cavalo, um capote também de pano preto com mangas, gola em pé e cabeção, e um chapéu de lã parda braguês, cujas largas abas estavam presas à copa por dois colchetes.

0 cuidado de furtar-se às vistas de pessoas estranhas deram-lhe o habito de ir de madrugada para o lugar em que tinha de trabalhar e voltar à casa depois de fechada a noite (Bretas, 1951: 23-26).

Afinado com uma escrita retórica, costume da época, e ao sabor do mais autêntico gosto romântico, Bretas descreveu Aleijadinho como o Quasímodo mineiro, denuncia Sônia Maria Fonseca:

Aleijadinho emerge das palavras de Bretas, como uma disforme criatura, algo semelhante a uma figura monstruosa, quasimodesca, porém dotada de talento e compaixão com aqueles de seu convívio íntimo. Furtava-se à vista das pessoas trabalhando às ocultas (como o sineiro de Notre Dame) deslocando-se em Vila Rica nos períodos noturnos (Quasímodo é acusado de caminhar sobre os telhados à noite). A figura quasimodesca descrita por Bretas surge como uma criação de sentido mais literário do que uma descrição verossímil das condições meramente físicas de Aleijadinho. Grotesco e sublime, primitivo e popular, gótico e barroco, transgressor e canônico, dócil e irascível, genial e demoníaco, sombrio e iluminado. Trágico pela doença e afortunado pelo talento. Não pode haver 
"entidade mais ideal" no espírito romântico do que aquela portadora de contradições e dicotomias. Aleijadinho é o ideal grotesco (como Quasímodo) (Fonseca, 2008: 03).

Como visto, ao longo do texto de Bretas abundam alusões à monstruosidade de sua aparência e a genialidade de sua obra, assim como ao seu temperamento apaixonado e arrebatado que diante das dificuldades para esculpir impostas pela doença, chegava a cortar os próprios dedos. Tal biografia, mais uma peça literária, escrita segundo seu autor a partir do testemunho da nora de Aleijadinho, foi acolhida pelos intelectuais modernistas sem maiores reservas e transformada pelo Serviço de Patrimônio Histórico e Artístico Nacional, o SPHAN em "documento-monumento" como sublinhou Sônia Fonseca (2008).

Mário de Andrade, figura central do movimento modernista, como se sabe, foi um grande estudioso da nossa arte colonial. Em 1920, Andrade publicou na Revista do Brasil uma série de quaro artigos reunidos com o título Arte religiosa no Brasil. A despeito de sua incerteza inicial sobre o barroco, interessa-nos especialmente suas considerações sobre Aleijadinho. Aqui, o Aleijadinho de Mário é o mesmo Aleijadinho de Bretas:

Toda a Minas religiosa está tão impregnada da sua genialidade, que se tem a impressão de que tudo nela foi criado por ele só. Esse mísero, feíssimo, corcunda, baixote, sem mãos, amarrando nos cotos dos braços os instrumentos com que fazia explodir da pedra sabão as visagens dos seus romanos e borboletear o sorriso alado de seus arcanjos (apud: Gomes Jr, 1998: 55).

Em 1928, Mário escreveu seu primeiro artigo especialmente dedicado ao genial Aleijadinho ${ }^{3}$. Realizaria uma análise sociológica da condição do mulato na colônia sobreposta à noção romântica do artista genial capaz de transpor barreiras impostas pela origem de classe, pelo preconceito racial e pela doença que o deformava. A doença, tendo aparecido na maturidade, revelaria um Aleijadinho expressionista uma categoria estilística trans-histórica que explicaria um Aleijadinho gótico e deformador:

(...) o aparecimento da doença divide em duas fases nítidas a obra do Aleijadinho. A fase sã de Ouro preto e São João Del Rei se caracteriza pela serenidade equilibrada e pela clareza magistral. $\mathrm{Na}$ fase de Congonhas, do enfermo, desaparece aquele sentimento renascente da fase sã, surge um sentimento muito mais gótico e expressionista (Andrade, 1965: 35).

Assim, o Aleijadinho de Mário ia da clareza renascentista ao expressionismo, superando a arte barroca luso-colonial, apresentando-se de fato como um precursor da nacionalidade: "Já se distingue das soluções barrocas luso-coloniais, por um tal ou qual denguice, por uma graça mais sensual e encantadora, por uma "delicadeza" tão suave, eminentemente brasileiras" (Andrade, 1965: 34). E, conforme as palavras de Gomes Jr. "tudo se arremata(va) na nova valorização do composto racial brasileiro" (Gomes Jr, 1998: 57) pois, para Mário, Aleijadinho era "a solução brasileira da Colônia, (...) o mestiço (...) e a independência" (Andrade,1965: 45).

Atendendo à solicitação do então ministro da Educação e Saúde Pública, Gustavo Capanema, em março de 1936 Mário de Andrade concluiu o projeto do "Serviço de Patrimônio Artístico Nacional". No 
mês seguinte, o presidente da República autorizava, em caráter experimental, o funcionamento do SPHAN sob a direção do jornalista Rodrigo de Mello Franco de Andrade, que ali permaneceria até 1967. A criação do SPHAN foi oficializada em lei promulgada em janeiro de 1937 - Lei n. 378 (SPHAN resumo cronológico,1987). É importante lembrar que quase dez anos antes da criação do SPHAN, em 1928, Rodrigo de Melo Franco já integrava o grupo de intelectuais "partidários" da arte colonial brasileira. 0 jornalista havia dedicado um número especial do jornal que dirigia, O Jornal, a Minas Gerais. Tal edição contava com artigos de, entre outros expoentes do modernismo brasileiro, Mário de Andrade ("O Aleijadinho"), Manuel Bandeira e Lucio Costa. Assim, como notório, o SPHAN nasceu no seio do modernismo brasileiro, tornando muito oportuna a observação feita certa vez por Sérgio de Micelli de que o SPHAN seria "um capítulo da história intelectual e institucional da geração modernista" (Miceli,1987: 44).

Tão logo o SPHAN passou a funcionar, Rodrigo de Mello Franco de Andrade solicitou a Manuel Bandeira que escrevesse um guia de Ouro Preto. Em 1937, Bandeira escreveu seu famoso Guia de Ouro Preto, sendo publicado em 19384. Bandeira dedica uma parte de seu guia a Aleijadinho. De saída, esclarece que o que se conhece da vida do escultor foi apurado por seu único biógrafo Rodrigo José Ferreira Bretas. Fiel ao biógrafo do século XIX, Bandeira narra a origem portuguesa de Aleijadinho, filho de escultor português, chamando a atenção para sua mestiçagem: era "pardo-escuro". O poeta descreve a aparência física de Aleijadinho tal qual Bretas o fez, e ressalta que antes da doença 0 escultor mineiro levava uma vida boêmia: "até a idade madura gozou de perfeita saúde, de que abusava aliás, sendo grandemente dado aos vinhos, às mulheres e aos folguedos populares" (Bandeira, s.d: 68). Refere-se à doença que o desfigurou e o mutilou, repetindo a imagem da auto-mutilação dos dedos. Também, encontramos aí a imagem do Aleijadinho andando de joelhos devido à queda dos dedos do pé, e com as mãos amarradas ao martelo e cinzel pela falta dos dedos das mãos. Bandeira descreve um homem forte apesar da tragédia em que vivia. Aleijadinho mantinha a força moral e a grandeza do engenho: "Todavia, a enfermidade, longe de abater o ânimo de Antônio Francisco, como que estimulou a sua extraordinária capacidade de trabalho. 0 principal efeito dela foi segrega-lo da sociedade, que êle passou a evitar" (Bandeira, s.d:71).

Investindo na descrição do gênio moderno, Bandeira insiste na associação de uma inclinação moral às desventuras biográficas como concorrentes à sua genialidade artística e ressalta a "brasilidade" da produção artística de Aleijadinho:

Entenda-se que o diminutivo de Aleijadinho é significativo da pura compaixão e meiguice brasileira. $O$ homem a que ele se aplicou nada tinha de fraco nem pequeno. Era, em sua disformidade, formidável. Nem no físico, nem no moral, nem na arte, nenhum vestígio de tibieza sentimental. Toda a sua obra de arquiteto e escultor é de uma saúde, de uma robustez, de uma dignidade a que não atingiu nenhum outro artista plástico entre nós. As suas igrejas, que apresentam uma solução tão sábia de adaptação do barroco ao ambiente do século XVIII mineiro, não criam aquela atmosfera não criam aquela atmosfera de misticismo quase doentio que há, por exemplo, em São Francisco de Assis, da Bahia, ou na Misericórdia, de Olinda: nas claras naves de Antônio Francisco dir-se-ia que a crença não se socorre senão da razão; não há nelas nenhum apelo ao êxtase, ao mistério, ao alumbramento (Bandeira, s.d: 72-73). 
Mário de Andrade, Manuel Bandeira, Lourival Gomes Machado (teórico da noção de "barroco mineiro"), e outros, compõem o quadro de intelectuais que de alguma forma gestaram e/ou endossaram as noções de tradição artística brasileira, barroco mineiro e o "mito" do Aleijadinho. Logo, a criação do SPHAN, no plano intelectual, é impensável longe do projeto nacionalista modernista - fundado no entendimento da arte colonial como verdadeira tradição artística brasileira e no reconhecimento da genialidade de Aleijadinho capaz de superar os modelos europeus e criar arte de altíssima qualidade genuinamente brasileira. Ora, certamente os nossos intelectuais sabiam das condições do negro no período colonial, da ausência ou, no mínimo, da precariedade do sistema de arte da época, pouco favorável à formação de grandes mestres. Somente a noção de gênio artístico oriundo do romantismo sustentaria aquela visão sobre o século XVIII - daí o acolhimento tão pronto da biografia de Aleijadinho escrita por Bretas. O gênio nacional que se manifestara em Aleijadinho seria identificado, por exemplo, em Oscar Niemeyer por Lúcio Costa. Em resposta à polêmica gerada pelo jornalista Geraldo Ferraz em artigo publicado no Diário de São Paulo em 1948, afirmando o pioneirismo de Gregório Warchavchick e Flávio de Carvalho na implantação da arquitetura moderna no Brasil, Lúcio Costa respondeu:

Não adianta, portanto, perderem tempo à procura de pioneiros (...); há precursores, há influências, há artistas maiores ou menores: e Oscar Niemeyer é dos maiores (...). No mais, foi nosso próprio gênio nacional que se expressou através da personalidade eleita desse artista, da mesma forma como já se expressava no século XVIII, em circunstâncias, aliás, muito semelhantes, através da personalidade de Antônio Francisco Lisboa, 0 Aleijadinho (Costa apud Baeta, 2005:12)

Em 1951, motivada pela descoberta do risco original da igreja da Ordem $3^{a}$ de São Francisco de Assis de São João del Rei, desenho insuspeitadamente atribuído à Aleijadinho, a Diretoria do SPHAN dedicou a $15^{\mathrm{a}}$ edição de sua revista à nova publicação do texto de Bretas, precedido por artigo introdutório de Lúcio Costa intitulado "Introdução - A arquitetura de Antônio Francisco Lisboa revelada no risco original da capela franciscana de São João del Rei" (Bretas, 1951). Esta nova edição pretendia por fim de vez a qualquer possível questionamento sobre a veracidade deste documento, pois ostentava orgulhosamente nada menos que oitenta e três notas. Conforme a Explicação Preliminar, as notas eram de

autoria de Rodrigo M. F. de Andrade, Lúcio Costa, e principalmente de Judite Martins, estas baseadas na bibliografia impressa sobre 0 assunto e, em grande parte, em documentos inéditos coligidos nos arquivos mineiros pelos Srs. Manuel José de Paiva, Salomão de Vasconcelos, Francisco Antônio Lopes, Antonio Ferreira de Morais, Padre José Higino Freitas e outros (Bretas, 1951: 9).

O enorme esforço realizado pelos pesquisadores do SPHAN, liderados por Rodrigo de Melo e Franco, junto aos arquivos mineiros para comprovar o caráter de documento fidedigno do texto de Bretas, sedimentou a imagem de Aleijadinho como 0 artista genial, inspirado, criador de obras originais. Sedimentou a imagem de Aleijadinho criada por Bretas no século XIX.

Se a imagem de Aleijadinho defendida pelo SPHAN foi preponderante, isso não corresponde a afirmar que não tenha havido na época vozes discordantes. O debate sobre a veracidade dos "fatos" descritos por Bretas em sua biografia de Aleijadinho, cabe ressaltar, teve início já fins dos anos 1930 e teve na 
figura de Roger Bastide um importante interlocutor ${ }^{5}$. Tendo se transferido para o Brasil em 1938 para assumir a cadeira de sociologia na Faculdade de Filosofia, Ciências e Letras da USP, logo Bastide refletiu sobre o barroco brasileiro e analisou a figura de Aleijadinho. Em 1941 publicou Psicanálise do Cafuné, um livro de ensaios entres os quais "O Mito do Aleijadinho" e "Sociologia do Barroco no Brasil". Tomando por base o texto de Bretas e analisando a figura do artista sob o prisma das representações coletivas, Bastide compreendeu o caráter mítico atribuído ao artista. Sem propriamente questionar a veracidade das fontes usadas por Bretas como o testemunho da nora de Aleijadinho ou a existência do relato do vereador de Mariana (pontos questionados pela historiografia recente), Bastide concluiu que aquela era uma imagem construída pelo povo local, uma espécie de lenda comum na representação de artistas, portanto falsa do ponto de vista da exatidão do documento. Para o sociólogo francês, tal representação de Aleijadinho coincidia com a representação tradicional e universal na qual o artista seria sempre marcado por um destino terrível.

Segundo Gilda de Mello e Souza, aluna do sociólogo em seus cursos na USP, Bastide, à la Conan Doyle, analisava e descartava as informações que se pretendiam "precisas", como a lepra que, segundo o relato de Bretas, havia lhe levado os dedos necessitando ao final da vida - momento em que esculpiu os profetas de Congonhas - que as ferramentas de trabalho lhe fossem amarradas às mãos (ou ao que sobrou delas) para que pudesse esculpir. Como então conseguiria realizar trabalho de tamanha quantidade e qualidade, questionava Bastide. E mais, analisando suas assinaturas em recibos de pagamentos pelas esculturas dos Passos da Paixão de Cristo e dos Profetas, o escultor teria começado a empresa aos 46 anos e terminado aos 75 anos, Bastide concluiu que não havia alterações em sua caligrafia que concordassem com as mutilações causada pela doença descrita por seu biógrafo. Ao contrário, sua caligrafia Ihe pareceu perfeita (Bastide, 1941).

Um fato curioso, apesar de poucas informações a respeito, é uma carta endereçada a Roger Bastide em maio de 1954 por Murilo Mendes. Esta parece ser uma resposta à carta de Bastide recebida recentemente, o poeta se encontrava em Bruxelas e Bastide em Paris. Em tom cerimonioso, diferente do tratamento aos correspondentes mais íntimos em que normalmente chama de "querido amigo" ou "caro amigo" etc, Murilo se dirige ao sociólogo francês como "Caro Professor Roger Bastide" (Guimarães, 2012: 75). Na carta, Murilo explica ao professor que, por não saber se o encontraria em Paris, enviou o livro que ele Ihe havia emprestado, com mais dois números da revista Estudos Brasileiros, pelo amigo em comum Paulo Carneiro (embaixador do Brasil junto a Unesco). Infelizmente não se sabe a qual livro o poeta se refere, mas, de todo modo, nos permite supor que o pensamento de Bastide não foi indiferente ao nosso poeta. Teria a visão de Bastide sobre o Aleijadinho influenciado de alguma maneira Murilo Mendes? Ou seria mesmo o Aleijadinho de Murilo uma atualização do Aleijadinho de Mário de Andrade, Manuel Bandeira e do SPHAN? Sabendo que Murilo Mendes não foi propriamente um defensor de uma arte nacional à la Mário de Andrade, embora nos anos 1940 e início dos 1950 tenha defendido uma arte socialmente engajada e tenha refletido sobre a tradição cultural do Brasil, uma vez que sempre afirmou o caráter universal da arte, como o poeta concebe 0 Aleijadinho? Vejamos. 


\section{O Aleijadinho por Murilo Mendes}

Em duas ocasiões Murilo descreveu Aleijadinho: em História do Brasil (1932) e Contemplação de Ouro Preto (1949-50). Em Força de Aleijadinho, poema de História do Brasil, Murilo refere-se à "mão doente" e "homem disforme e triste" (Mendes, 1994: 159). Em Contemplação de Ouro Preto, Aleijadinho é referido muitas vezes, já num contexto de afirmação do barroco mineiro. No poema Motivos de Ouro Preto, ao cantar a Igreja São Francisco de Assis, Murilo escreve: "Seus ornamentos sóbrios sintetizam I Do barroco mineiro a austera força. / Assim o esculpiu na tradução humana / $O$ escopro genial do Aleijadinho (Mendes,1994: 460). No poema Romance de Ouro Preto, dedicado a Manuel Bandeira, Murilo descreve Aleijadinho em longo verso. O Aleijadinho se confunde com a cidade de Ouro Preto: "Do Aleijadinho / - Pernas de pedra, / Tronco de igreja, / Testa de morro". Reconhecendo o artista moderno Aleijadinho, autor que imprime em sua obra traços de sua personalidade, Murilo escreve: "Do Aleijadinho, / Macho escapado / Ao próprio escopro, / - Sua obra inteira / É auto-retrato / De corpo inteiro / Revelador -," E a seguir repete a imagem criada por Bretas e difundida por Bandeira em seu Guia de Ouro Preto: "Do Aleijadinho / Severo ancestre / Mal-encarado, / Encapuzado / No seu furor, / Alma barroca, / Fundos refolhos / De obscura raiva / Guardando em si, / Na dura entranha / De penha humana / Com fortes peitos / Gerado à luz". Certamente, tal imagem lhe possibilitava unir sua escrita de tendência surrealista com a imagem do barroco, "alma" tanto de Aleijadinho como de Ouro Preto. Por outro lado, como lemos mais adiante, Murilo expõe sua noção de arte cuja função é equilibrar os opostos, cálculo e fantasia, razão e sensibilidade, num exercício de liberdade:

Do Aleijadinho / Força fogosa, / Grã-liberdade / Na disciplina / Do antigo amor / Movendo os dedos, / Movendo o engenho / Com seu vigor, / Força madura, / Fundamental, / Que à alma imprime/ Imperecível / Sempre impassível, /Grave postura, / Nobre feição, / Do Aleijadinho / -Simplicidade / Dentro do excesso, / Transbordamento / Não sem rigor (...) (Mendes, 1994: 484).

Também no poema São Francisco de Assis de Ouro Preto, dedicado à Lúcio Costa, o poeta identifica na forma da igreja o equilíbrio entre razão e imaginação, indicando uma superação da forma arquitetônica em relação ao modelo português: "Solta, suspensa no espaço, / Clara vitória da forma / E de humana geometria / Inventando um molde abstrato; / Ao mesmo tempo, segura, / Recriada na razão, / Em número, peso, medida; / Balanço de reta e curva, / Levanta a alma ligeira, / À sua pátria natal". A seguir, usando a imagem de Bretas e Bandeira, identifica Aleijadinho como o autor da obra: "Repouso da cruz cansada, / Signo de alta brancura, / Gerado, em recorte novo, / Por um bicho rastejante, I Mestiço de sombra e luz". E Murilo termina o poema descrevendo a igreja, obra de Aleijadinho, como "aposento da Trindade e da Virgem Maria" (possivel alusão à talha esculpida por Aleijadinho no arcocruzeiro desta igreja) e atribuindo ao escultor a condição de herói, não só pelo seu grande feito artístico, mas por uma dimensão transcendente, religiosa que une Deus ao homem: "Aposento da Trindade / E mais da Virgem Maria / Que se conhecem no amor; / Traslado, em pedra vivente, / Do afeto de um sumo herói / Que junta o braço do Cristo / Ao do homem seu igual" (Mendes, 1994: 490).

Murilo também dedicará um poema ao escultor mineiro: Ao Aleijadinho. Aqui salienta em Aleijadinho a devoção fervorosa como o havia afirmado Manuel Bandeira (e Bretas): "Sabe-se que depois de adulto a sua principal leitura era a Bíblia, alimento de sua arte, toda ela de inspiração religiosa" (Bandeira, s.d.: 68). No poema de Murilo, lemos: "O exemplo recebendo que ofereces / Pelo martírio teu enfim 
transposto, / Severo, machucado e rude Aleijadinho / Que te encerras na tenda com tua bíblia,I Suplicando ao Senhor - infinito e esculpido - / Que sobre ti descanse os seus divinos pés" (Mendes, 1994: 533). No Guia de Ouro Preto de Bandeira, lemos: "Os últimos meses de vida passou-os Antonio Francisco entrevado e cego, num pequeno estrado, três tábuas sobre dois cepos de pau, implorando continuamente o Senhor "para que sobre ele pusesse os seus divinos pés" (Bandeira, s.d.:72). A mesma cena foi descrita por Bretas: "Durante o tempo em que esteve entrevado, frequentes vezes apostrofava à Imagem do Senhor que tinha em seu aposento; e tantas vezes havia esculpido, pedindo-lhe que 'sobre ele pusesse os seus Divinos Pés'” (Bretas, 1951). Não sabemos se Murilo leu diretamente a monografia de Bretas, mas notícias de Aleijadinho provindas de seu primeiro biógrafo são encontradas em mais algumas passagens de Contemplação, como no poema Acalanto de Ouro Preto, dedicado a Guignard, onde refere-se a Aleijadinho liberto da Zamparina e com seus dois escravos Mauricio e Justino.

Em História Concisa da Literatura, Alfredo Bosi chama a atenção para que desde Sonetos Brancos (1948), Murilo mostrava sua "vocação para o real, tão forte que abraça(va) também o real-imaginário, 0 supra-real", o que o teria levado a aproximar-se dos objetos e paisagens buscando sua forma concreta (Bosi, 1984: 504). Para o intelectual, Murilo teria atingido o ápice com Contemplação de Ouro Preto onde, através da história e paisagem de Ouro Preto, "procura colher a essência mesma do barroco mineiro (...) e da arte de Aleijadinho feita de espanto e unção" (Bosi, 1984: 504). De fato, a história de Ouro Preto e de Aleijadinho se confundem, costuradas pela religiosidade católica. 0 signo religioso percorre toda obra, sendo um elemento "universalizante" que atravessa a memória do país. Neste sentido, a imagem de Aleijadinho herdada de Bretas e difundida pelo SPHAN é tomada como imagem simbólica de um artista brasileiro que participa da tradição universal, tanto pela religiosidade, quanto por seu gênio artístico. Aleijadinho, o mestiço mineiro, é concebido sob o viés da tradição ocidental de artista moderno.

Murilo interpreta a cultura nacional tensionada por sua história particular e por elementos universais como a religião católica, a imagem do gênio criador de Aleijadinho (imagem de artista universal), e mesmo a noção de barroco mineiro. Ora, barroco seria uma categoria universal que qualifica o particular arte e cultura mineira ${ }^{6}$. Julio Castañon Guimarães (1993) afirma que Murilo Mendes entendia não ser preciso afastar o nacional do universal. Tal posição fica clara quando recorremos aos textos críticos escritos nesta mesma época. Entre 1946 e 1951, Murilo Mendes colaborou com o jornal A Manhã, publicando artigos entre outros sobre Ismael Nery, Di Cavalcanti, Djanira, Lívio Abramo e Segall. Tais textos são muito significativos das suas preocupações estéticas e de seu entendimento da condição universal do trabalho artístico.

Em 1948 Murilo Mendes (1996) publicou uma série de 17 artigos sobre o amigo Ismael Nery e embora reproduza o ponto de vista de Nery, segundo Guimarães (1993), não é possível desvinculá-lo de seu próprio pensamento. Refletindo sobre a tradição artística brasileira e a arte "brasileira", define modernidade recorrendo ao conceito de Baudelaire. Tal noção lhe permitiu refletir sobre a tradição ou a dimensão histórica da arte moderna e encaminhar o tema do nacionalismo ao universalismo. Assim afirma: 
A arte brasileira dos anos 1916 a 1930 sofreu, como não podia deixar de sofrer, um choque de surpresa. Choque vindo da tomada de conhecimento da revolução moderna fenômeno de ordem geral e não apenas de ordem artística. Choque e crise. Crise nascida da necessidade de refletir as correntes europeias. Crise da adaptação das dominantes revolucionárias às possibilidades e ao ambiente do Brasil. (...) Vivendo quase todos no Rio ou em São Paulo, nossos artistas da época - pelo menos em sua grande maioria não tomaram contato com a tradição plástica colonial de Minas, Bahia e Pernambuco, de resto muito mais importante na parte da arquitetura e escultura, do que na de pintura. $A$ tradição do primeiro e segundo império era estática, pois vinha do frio academicismo gerado pela missão francesa do tempo de Dom João VI, que anulou o magnífico surto dos nossos santeiros populares, heróis obscuros e excluídos dos catálogos oficiais. Sem dúvida, Pedro Américo, Vitor Meireles, Amoedo e outros trabalharam e deixaram uma obra que se prolongou até os nossos dias em alguns pintores. Estes, entretanto, não transmitem em suas telas a palpitação da vida, nem sabem criar um estilo pessoal, pois se fixam em fórmulas convencionais ultrapassadas. (Mendes, 1996: 105-106)

Murilo passa então a refletir sobre os conceitos de modernismo e modernidade. Para o poeta, a palavra modernismo "restringe a área de um fenômeno positivo", por isso prefere o termo modernidade, pois como ensinou Baudelaire, o conceito engloba a compreensão do "poético no histórico" e o "eterno do transitório" (Mendes, 1996: 107). A modernidade na arte englobaria o transitório, o contingente de um lado e o eterno e imutável de outro. Por esse viés, entende a dimensão histórica da arte, expressa na sua universalidade. Assim, o poeta articula o elemento eterno, invariável, às novidades na arte:

Os mais recentes estudos críticos de pintura demonstram o encadeamento do processo da modernidade através dos séculos. Sabemos hoje que muitos elementos importantes da arte de Picasso, Braque, Bonnard e outros estão contidos pelo menos em germe nos primitivos medievais, nas pinturas bizantinas e mesmo em documentos mais remotos. Conhecemos agora a impressionante modernidade de Bosch, surrealista no século XVI; Arcimboldo, no século XVI, abriu caminho para Salvador Dali. E como explicar a súbita inclinação do mundo das artes para o esquecido El Greco - um verdadeiro coup de foudre - se não fora a sua modernidade patente? (Mendes, 1994: 108)

A modernidade é para Murilo uma espécie de categoria que transcende ao tempo linear. "Os maiores artistas da humanidade" estão dentro e fora do tempo, uma vez que guardam aspectos transitórios e eternos. Atribuindo à campanha artística iniciada em 1922, a inauguração no Brasil da modernidade, vê em Aleijadinho um artista universal, o germe da modernidade brasileira.

Discutindo sobre a expressão do nacional na arte, Murilo chama a atenção para a produção pictórica de Ismael Nery durante 1927 e 1929, marcada por um "lirismo brasileiro e o russo" (Mendes, 1994: 116). Os desenhos e pinturas de Nery deste período se assemelham às Bachianas de Villa Lobos: "um contraponto em que se alternam motivos e temas de países diferentes, fundidos na constelação superior do céu da arte, acima das fronteiras de nacionalidade, provando a unidade espiritual do gênero humano através da variedade, dos pormenores e da fisionomia própria de cada povo e de cada artista (Mendes, 1994: 16).

Argumenta não ser possivel adotar o mesmo formato plástico para expressar uma arte nacional, uma vez que as diferenças sociais e culturais devem ser consideradas. Toma como exemplo o muralismo 
mexicano e mesmo a arte feita pelos negros. Entendia que o muralismo mexicano era estrutural na sociedade mexicana, mas não no Brasil, opondo-se assim a uma corrente que defendia tal expressão. Quanto ao negro, considerando a tradição plástica colonial, Murilo achava que "não dava bem em pintura", uma vez que a arquitetura e escultura eram muito superiores (ver transcrição acima). Através de Ismael Nery, o poeta ainda denuncia que o branco não teria como expressar a sensibilidade negra, algo só possível ao negro. Enfim, suspeitava que a pintura de tom nacionalista modernista estava superficial e anedótica.

$\mathrm{Na}$ época discutia-se muito o problema de uma construção plástica baseada em dados especificamente brasileiros. Isto era uma fase do processo de deseuropeização, a que se refere Mário de Andrade numa carta de 1925 a Manuel Bandeira, há dias publicada. Mas Ismael achava que a atitude de nossos artistas deveria ser diversa, por exemplo, da dos mexicanos (....). Quanto ao negro, dizia que não dava bem em pintura; além disto a sensibilidade negra só pode ser exprimida autenticamente por eles próprios. A pintura "brasileira" estava-se inclinando para o anedótico e a superficialidade. Sendo nosso país uma vasta soma de misturas de tendências, achava Ismael Nery que nós deveríamos construir no plano da universalidade duvidando de uma arte saída de uma vontade deliberada de "fazer brasileiro". E costumava dizer: 'Se sou brasileiro, minha arte refletirá necessariamente a psique brasileira; não adianta programa'. Daí, examinando nosso temperamento e nossas possibilidades históricas, Ismael partiu para a pesquisa de um tipo humano de caráter universal, transpondo essas preocupações nos seus quadros e desenhos (Mendes,1996: 116-117).

Alguns anos depois de escrever a série de artigos sobre Ismael Nery, Murilo volta a refletir sobre 0 modernismo brasileiro em uma espécie de revisão da atuação de Tarsila do Amaral. No "texto retrospectivo", como denominado por Guimarães (1993: 92), Tarsila, escrito entre 1965-1966 e publicado na primeira série de Retratos-Relâmpago, lemos: "Revendo Tarsila do Amaral em sua casa em São Paulo retorno ao Rio de 1929, à exposição histórica da pintora no Palace Hotel" (Mendes, 1994: 1249). Aqui o poeta reafirma seu entendimento de arte brasileira como síntese entre as culturas gerado pela modernidade:

Na década de 20 Tarsila efetua esta operação capital: por via da técnica europeia assimila o espírito caipira de São Paulo e Minas (...). Mais uma vez realiza-se uma síntese de culturas, de acordo com a nossa vocação e fatalidade histórica. Tarsila inaugura um eixo inesperado: Sabará-Paris. Encontram-se num território ideal Henri Russeau, Léger, Gleizes, Lhote e nossos ingênuos decoradores de capelas, arcas e baús, muito deles anônimos (Mendes, 1994: 1250).

No artigo sobre Di Cavalcanti, publicado em 1949, apuramos a noção de artista moderno operada por Murilo Mendes. Di Cavalcanti é descrito nos moldes do artista romântico, semelhante ao Aleijadinho, tem temperamento forte, boêmio, transgressor e ao mesmo tempo capaz de muita disciplina e rigor para trabalhar, sendo sobretudo livre: "Ora, esse feitio boêmio do temperamento de Di Cavalcante combinase com uma capacidade de trabalho (...). A arte de Di Cavalcanti, bem como sua pessoa humana, bem como seu método de ofício, está fundada na liberdade" (Cavalcanti, 1949: 5). Como Aleijadinho, o artista configura-se por seus opostos: "Eis o paradoxo de Emiliano Di Cavalcanti: este grande individualista é um pintor social, este boêmio dispersivo é um trabalhador obstinado, este contador de histórias 
pitorescas é um espirito sério capaz de disciplina" (Ibidem). Entretanto, tal espírito portador de tantas dicotomias, na lucidez de sua consciência artística ("atingiu um elevado nível da consciência artística"), acaba por resolver as contradições pela força de sua arte numa síntese da própria brasilidade:

Em alguns dos melhores momentos de sua carreira Di Cavalcanti atingiu pela força da verdade plástica 0 cerne da nossa própria verdade metafísica na unificação de seus contrastes: de fato a gente brasileira foi ali recriada em síntese erudita, como em passagens hoje clássicas para nós, do Aleijadinho, Castro Alves, Machado de Assis, Ernesto Nazareth, Villa-Lobos, Portinari, Manuel Bandeira, Cícero Dias, Mário de Andrade, Jorge de Lima e alguns poucos mais (Ibidem).

Murilo inclui Di Cavalcanti numa linha de artistas brasileiros cuja origem é Aleijadinho, reconhecendo uma tradição artística brasileira. Por sua vez, esses artistas, representantes da arte brasileira, se inserem no plano maior da cultura universal. Nacional e universal são opostos que se resolvem na síntese operada pela arte. Daí Murilo afirmar que Di Cavalcanti foi capaz de incluir o lirismo do Rio de Janeiro de outrora (não o Rio daquele tempo que se "americanizava", ao qual Murilo se opõe), com "suas componentes negras e portuguesas" no acervo universal da cultura. Assim, aproximar o nacional do universal era realizar a síntese entre a cultura europeia e a brasileira, o que Di teria feito com aguda inteligência e consciência artística através da técnica: "O aproveitamento da técnica de Escola de Paris transplantada com sabedoria para o terreno da pintura brasileira demonstra a aguda inteligência do nosso Di Cavalcanti, que assim coloca o nacional no universal" (Mendes, 1949: 5).

Ocupa o pensamento sobre arte de Murilo a busca de um equilíbrio ou síntese entre o cálculo e a espiritualidade, a razão e a sensibilidade, o nacional e o universal, logo, entre aparentes extremos. Embora Lasar Segall não seja um artista brasileiro, cuja obra é expressão de brasilidade, o artigo que Murilo escreve sobre Segall em 1951 nos apresenta uma passagem esclarecedora sobre seu conceito de universalidade. Sobre a brasilidade, vale frisar que Murilo confere a Segall o mérito de, ao pintar a natureza brasileira, ter produzido "uma mudança no eixo de interpretação da nossa natureza: 0 artista afastado das aparências superficiais, procura transpô-la de maneira elevada, anulando o fácil conceito de Brasil tropical, idéia excelente para cartazes turísticos" (Mendes, 1951: 01). Leia-se aí a crítica do poeta à pintura superficial e anedótica ao escrever sobre Ismael Nery.

A universalidade da arte provocaria uma identidade ou comunhão entre os diferentes homens, superando diferenças nacionais, pode-se dizer. Tal universalidade reside na qualidade plástica da obra, por isso Murilo vê em Segall um artista universal:

De resto, 0 alto padrão da obra de Segall fez inserir o nome do artista numa categorial universal de valor, de maneira que homens de todas as raças, crenças políticas ou religiosas se podem reconhecer nela; porque à segurança da construção plástica corresponde igual força de humanidade que transcende a todos os acidentes particulares. Isto é próprio dos grandes criadores (Ibidem).

Em Discípulo de Emaús, obra de 1945, Murilo já advertia: "Sem compreender o particular não se pode atingir o universal" (Mendes, 1994: 842). Murilo entendia ser função da arte promover a unidade espiritual do gênero humano. 
É certo que Aleijadinho cantado por Murilo em Contemplação é uma imagem poética. Também é evidente que a imagem "quasimodesca" de Aleijadinho descrita por Bretas e consolidada pelo SPHAN era material fértil para o poeta. De todo modo, deixa entrever um entendimento de artista portador de contradições e que se alimenta de oposições para resolvê-las no plano plástico. Provido de espírito universal é capaz de alcançar através de suas particularidades o campo da cultura universal. Sob condições particulares, o gênio do artista universal desabrochou num colono descendente de africanos que compreendeu e superou o modelo artístico europeu, mais especificamente lusitano, pois realizou a síntese entre razão e sensibilidade, entre o tempo transitório e o eterno, e assim, entre o nacional e 0 universal.

\section{Referências}

ANDRADE, M. de. O Aleijadinho. In: Aspectos das Artes Plásticas no Brasil. São Paulo: Martins, 1965.

ARAGÃo, M. L. Murilo Mendes - Poesia. São Paulo: Agir, 1983.

BAETA, R. E. A crítica de cunho modernista à arquitetura colonial e ao barroco no Brasil: Lúcio Costa e Paulo Santos. In: Anais do XXIV Colóquio Comitê Brasileiro de História da Arte. Belo Horizonte: UFMG/CBHA, 2005.

BASTIDE, R. Psicanálise do cafuné. São Paulo: Guaíra, 1941.

BRETAS, R. J. F. Traços biográficos relativos ao finado Antônio Francisco Lisboa, distinto escultor mineiro, mais conhecido pelo apelido de Aleijadinho. In: Antônio Francisco Lisboa, O Aleijadinho. Publicações da Diretoria do Patrimônio Histórico e Artístico Nacional. Rio de Janeiro, SPHAN/ MEC, 1951, n. 15.

BOSI, A. História concisa da literatura brasileira. São Paulo: Cultrix,1984.

FERNANDES, A. C. F. A. Por uma arte brasileira: modernismo, barroco e abstração expressiva na crítica de Lourival Gomes Machado. Tese (Doutorado em Artes Visuais). São Paulo: ECA USP, 2012.

FONSECA, S. M. O Romantismo e a invenção de Aleijadinho. In: Anais do XXVIII Colóquio do Comitê de História da Arte. Rio de Janeiro: CBHA, 2009.
GRAMMONT, G. Aleijadinho e o aeroplano: o paraíso barroco e a construção do herói colonial. São Paulo: Dep. de Letras Vernáculas/ FFLCH/ USP, 2002.

GUIMARÃES, J. C. Territórios/Conjunções. Poesia e prosa críticas de Murilo Mendes. Rio de Janeiro: Imago, 1993.

(org.). Cartas de Murilo Mendes a correspondentes europeus. Rio de Janeiro: Fundação Casa de Rui Barbosa, 2012.

GOMES Jr, G. S. Palavra Peregrina. O Barroco e o pensamento sobre artes e letras no Brasil. São Paulo: Editora da USP, 1998.

MENDES, M. Murilo Mendes, poesia completa e prosa. Org. Luciana Stegnano Pichio. Rio de Janeiro: Nova Aguilar, 1994, 4 vol.

Recordações de Ismael Nery. São Paulo: Editora da USP, 1996. (Críticas Poéticas 4).

Di Cavalcanti. Letras e Artes, Suplemento de A Manhã. Rio de Janeiro, 06 fev. 1949.

Lasar Segall - I. Letras e Artes, Suplemento de A Manhã. Rio de Janeiro, 20 mai. 1951, p.1.

Importância de Segall - II. Letras e Artes, Suplemento de A Manhã. Rio de Janeiro, 27 mai. 1951, p.1. 
Força e Unidade em Segall - III

(Conclusão). Letras e Artes, Suplemento de A Manhã. Rio de Janeiro, 03 jun. 1951, p.6.

MICELI, S. SPHAN: refrigério da cultura oficial. In: Revista do Patrimônio Histórico e Artístico Nacional 22. Rio de Janeiro: SPHAN/ Fundação nacional Pró-Memória, 1987.

MOURA. M. M. de. Murilo Mendes - a poesia como totalidade. São Paulo: EdUSP, 1995.
SPHAN resumo cronológico. Revista do Patrimônio Histórico e Artístico Nacional, n. 22. Rio de Janeiro: SPHAN/ Fundação Nacional Pró-Memória, 1987.

SOUZA, V. Murilo Mendes: da história satírica à memória contemplativa. Tese (Doutorado em Teoria Literária e Literatura Comparada). São Paulo: FFLCH/USP, 2006.

\title{
Notas
}

\begin{abstract}
* Professora do Programa de Pós-Graduação em Artes, Cultura e Linguagens da UFJF; Coordenadora do grupo de pesquisa "O acervo de artes visuais do Museu de Arte Murilo Mendes/UFJF"; e.mail: <raquinet.rqp@gmail.com>. ORCID: <https://orcid.org/0000-00023163-3842>.

${ }^{1} \mathrm{Na}$ edição original de Contemplação de Ouro Preto de 1954, Murilo Mendes registra, após o último poema, lugar e data de escrita "Ouro Preto - Mariana - Rio 1949-1950". Tal inscrição nos permite supor que a viagem à Ouro Preto com Cortesão possa ter ocorrido neste momento; ou ainda que a viagem que fez com sua irmã pode ter sido registrada erroneamente pelo cunhado, uma vez que Paulo Torres escreveu suas memórias já com seus 90 anos. Ademais, o próprio Torres afirma em suas memórias que achava que aquela viagem correspondia a um "momento de gestação" de Contemplação de Ouro Preto (Torres, 2005: 299).

2 Em 1949, Lourival Gomes Machado publicou uma espécie de guia de Ouro Preto com o título Viagem a Ouro Preto na Revista do Arquivo Municipal, São Paulo.

3 Uma primeira versão deste artigo foi publicado em O Jornal em 1928. Em 1935, será publicado com algumas modificações sob o título "O Aleijadinho e sua posição nacional", no livro O Aleijadinho e Álvares de Azevedo. Rio de Janeiro, R.A. Editora, e será reeditado em 1943 em Aspectos das Artes Plásticas no Brasil.

${ }^{4}$ O Guia de Ouro Preto é um desdobramento das crônicas publicadas por Bandeira nos jornais A Província, do Recife, Diário Nacional, de São Paulo e O Estado de Minas, de Minas Gerais. Também deriva de dois textos do livro "Da Vila rica de Albuquerque à Ouro Preto dos estudantes" de 1929, e "Aleijadinho", publicado em 1928 e republicado em 1930, onde sobressaem-se as influências de Mário de Andrade (Menezes, 2016).

${ }^{5}$ Antes de Roger Bastide, José Mariano Filho já apontava certas incongruências na versão de Bretas. Em 1940, ele publicou "Uma vítima da Imaginação Popular".

${ }^{6}$ Vale lembrar que Murilo possuía em sua biblioteca um exemplar de Du Baroque de Eugenio D'Ors de 1936. Ademais, segundo Ana Cândida Fernandes, o conceito de barroco mineiro teorizado por Lourival Gomes Machado resultaria numa busca do historiador da arte por "uma síntese entre tendências particularistas e universalistas", fruto de uma mudança de interpretação durante os anos 40/50 na qual Machado se aproximaria mais das teorias de Roger Bastide (Fernades, 2012:117).
\end{abstract}

Artigo recebido em fevereiro de 2020. Aprovado em abril de 2020. 